\title{
Automatic Card Punching Machine for Jacquard Machine
}

\author{
By Ichiro Ohno \\ Based on the Journal of the Textile Machinery Society of Japan, (Part 1) Vol. 18, No. 5, 373- \\ 380 (Part 2) Vol. 18, No. 7, 487-492 (1965)
}

\section{Introduction}

This article describes a method to produce designs by direct card punching without manual drafting on section paper which the existing method involves. Direct card punching requires that an electric conductive color be used for design-painting so that the design may be picked up electrically. It was found card is automatically punched by an electric sign.

The performance of our new method has been compared with that of the existing method, and the comparison has shown that our new method has a practical value.

\section{Part 1 Basic Problem}

\section{Purpose of New Method and How to Use it}

Pattern card punching by the existing common me. thod follows" this order :

1) Draw a design.

2) Select section paper suited to the density of warp and weft.

3) Draw an enlarged figure of the design on tracing paper.

4) Copy the enlarged figure on section paper.

5) Mark the weave points of the ground and figure weaves of the design copied on section paper.

6) Punch cards with the "piano machine" in line with the weave points marked on section paper.

The author replaces the foregoing process with the following automatic punching system:

1) Draw a design (by the existing method).

2) Put the design directly on the "piano machine," feeding the design paper to the machine by adjusting the driving wheels to the density of warp and weft.

3) The machine electrically picks up the figure and punches cards automatically according to electrical directions.
This leaves the weave points undrawn in the design. The remedy is to commit every weave point of the ground and figure to memory by a memory apparatus for use as needed.

Peg holes, e.g., binding holes, selvage holes, shuttlechange holes and heald holes in cards must be punched at the same time with the figure holes. However, our method dispenses with section paper and, therefore cannot draw these holes. In other words, our method is not equipped to pick up these holes atomatically. This is a problem which still awaits a solution.

After all, the automation consists of mechanism and electricity, and nothing new theoretically. The basic aim of our machine is to produce figures as accuratey without the use of section paper as with the use of it. The present study is to see how far this basic aim can be achieved. To carry out the study, we devised a model automatic apparatus as well as one to memorize the figure weave that cannot be drawn on the ori. ginal design.

\section{Direct Punching from Design}

The conventional method of picking up designs and pictures is to use a photo-electric converter extracts electrical pulses from the dark and light colours of a design. We tried this method in our study.

We used also electric conductive colours to draw designs. The method is to let a contact piece sweep the figure so as to obtain directions for card-punching from the on-off of electric conductivity. This method is simpler than the one using photo electric converter and makes it possible to see sweeping points from the outside.

Published works on electronics suggest other methods, including one which uses magnetic ink, but a problem common to all methods is the degree of fidelity with which the border lines around a figure can be picked up. Pick-up by electricity perceives the border lines at random and usually makes them show irregularly in a fabric.

Card-punching by hand picks up border lines ex- 
actly according to the sections of section paper. Pickup by photo-electricity is better than electric conductive colours because it reduces the diameter of the spot light.

\section{Outline of Autoratic Punching Machine}

There are two ways to making a pattern card:

A) Punch weave points simultaneously with figures - as is done on figured taffeta, damasks, flgured mulsine, figured silk Habutae, figured blankets, etc.

B) Punch only figures and let healds control gro. und weave-as is done on Japanese "obi" (sash), hand-woven brocade, figured carpets, etc.

Automation of method $\mathrm{A}$ is applicable to method B-but not vice versa. Therefore, our interest is in automatic card-punching for method A. The author works for a Japanese woollen textile mill and, as is his wont, takes up an automatic machine for figured blankets.

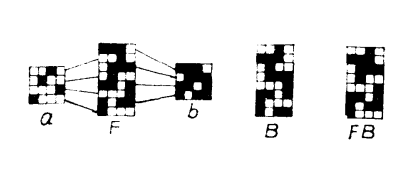

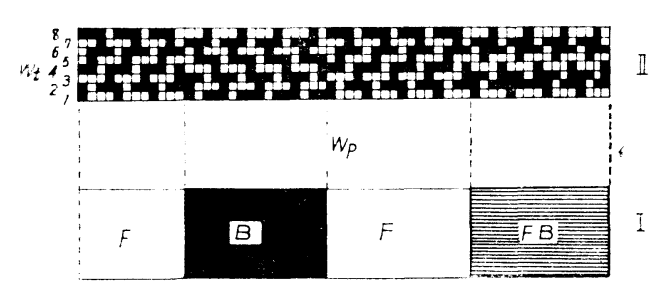

Fig. 1 Relation between pattern weave and figure

Fig. 1 shows the relation between the design and the weaving pattern of a figured blanket.

Fig. 1-(a) shows the face yarn weave and $\frac{1}{3}$ broken twill. Fig. 1-(b) shows the back yarn weave and $\frac{3}{1}$ broken twill. The two weaves are combined to make a weft double weave.

$F$ shows a face weave made by a combination of (a) and (b). B shows the back weave of F. Combining $\mathrm{F}$ and $\mathrm{B}$ alternately produces a weave such as is shown by $\mathrm{FB}$, which is a figure of neutral colour.

Coloring weaves F, B and FB separately gives us Fig. 1-I. And when we apply weaves to the portion of colours (I), we get Fig. 1-II. Therefore, pattern cards should be punched as shown in Fig. 1-II.

Table 1 shows only the weave points to be punched for one repeat weave in Fig. 1-II. One repeat weave is completed with 8 insertions of the weft yarn. The conventional method requires that the weave points
Table 1 Weave of Figured Blanket

\begin{tabular}{|c|c|c|c|c|c|c|c|c|c|c|c|c|}
\hline \multirow[b]{2}{*}{ NEFT No. 1} & \multicolumn{4}{|c|}{$\begin{array}{c}\text { GROUND WEAVE } \\
\text { WHITE }\end{array}$} & \multicolumn{4}{|c|}{$\begin{array}{l}\text { FIGURED WEAVE } \\
\text { BLACK }\end{array}$} & \multicolumn{4}{|c|}{$\begin{array}{l}\text { FIGURED WEAVE } \\
\text { GRAY }\end{array}$} \\
\hline & 0 & & & & 0 & & 0 & 0 & 0 & & & \\
\hline 2 & 0 & & $\mathrm{O}$ & 0 & 0 & & & & 0 & & 0 & 0 \\
\hline 3 & & & & 0 & 0 & 0 & & $0 ?$ & 0 & $\mathrm{O}^{--1}$ & & 0 \\
\hline 4 & 0 & 0 & & 0 & & 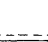 & . & 0 & & & & 0 \\
\hline 5 & & 0 & & & & 0 & 0 & 0 & & 0 & & \\
\hline 6 & & 0 & 0 & 0 & & 0 & & & & $\mathrm{O}$ & 0 & 0 \\
\hline 7 & & & 0 & & 0 & 0 & 0 & & 0 & 0 & 0 & \\
\hline 8 & 0 & 0 & 0 & & & & $\mathrm{O}$ & & & & ㅇ. & \\
\hline
\end{tabular}

note: $\square$ or ${ }_{\text {Shows the same weave }}$

in Table 1 be marked on section paper. We omitted section paper; the weave points must be memorized by some other method for use as and when needed.

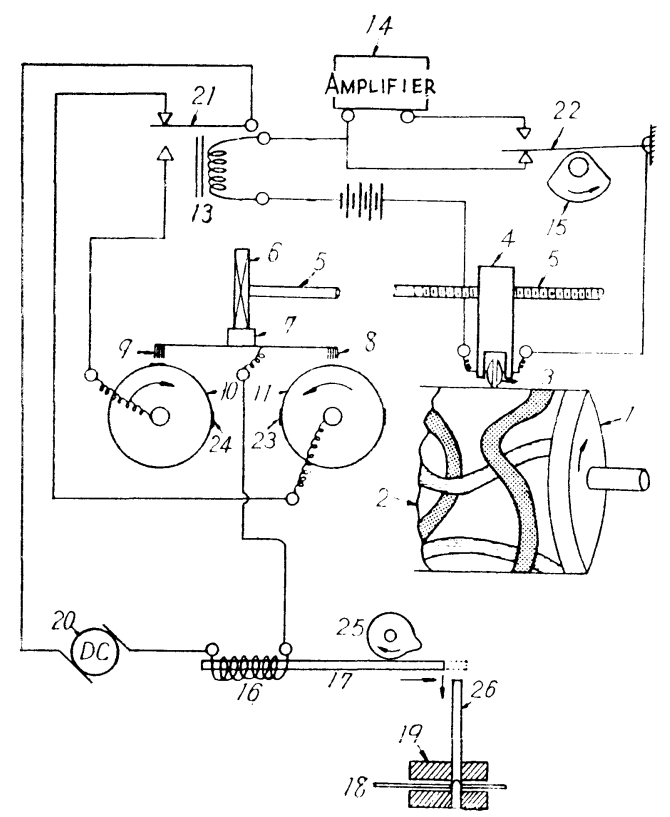

Fig. 2 General outline of automatic punching machine

Fig. 2 shows the principle of our punching machine which perceives colour and punches cards according to memorized weaves. Design 2 is fixed on drum 1 in order for the weft direction of the design to make the right angle to the drum shaft. The drum rotates intermittently at intervals of about $1 \mathrm{~mm}$. on the drum surface.

The design is painted in electric conductive colour and picked up by sweeping wheel 3 which is mounted on lever 4 to be driven by screw 5 for a distance 
equaling the length of one strand of the weft yarn (about $1 \mathrm{~mm}$ ). This example, being a weft double-weave blanket, in-volves 2 rotations, i.e., one rotation for face weave card punching and the other for back weave card. punching. The moving distance of the sweeping wheel is, of cource, adjustable to the weft density.

Switch 22 is controlled by cam 15 which rotates by $1 / 4$ circumference at every drive. This switch contacts amplifier 14 when the sweeping wheel sweeps the grey-color areas of the design (wefts Nos. 3, 4, 7 and 8 in Table 1).

Cylinders 10 and 11 are a kind of rotary switch. Electric conductors 23 are stuck on the surface of cy. linder 11 at every $1 / 4$ th of the circumference of the cylinder. Electric conductors 24, too, are stuck on the surface of cylinder 10 . Conductors 23 are for the ground weave points in Table 1 ; conductors 24, for the black weave points. Brushes 8 and 9 contact the cylinder surface and are held by rack 7 which is driven by gear 6 in the shaft direction of cylinders 10 and 11 .

Gear 6 is mounted on screw 5 which drives sweeping wheel 3. The wheel moves pitch by pitch. Rack 7 moves accordingly. (The moving direction is vertical in Fig. 2) The weave structure is repeated upon completion of every 8 insertions of the weft yarn. Rack 7 is then released from gear 6 to return to its original position.

Finger rod 17 is swung by solenoid 16 to the direc. tion of the arrow so as to stretch over the punch rod. When cam 25 presses down rod 17, the punch rod punches cards 18 . chine.

Here is the motion analysis of our punching ma-

(1) While sweeping wheel 3 is contacting the ground weave area of the design (shown in white which has no electric conductivity):

a) Switch 22 remains neutral,

b) Relay 13 stops working,

c) Switch 21 contacts with the upper terminal,

d) Cylinder 11 which memorizes the ground acts on solenoid 16 for punching according to the weave points.

(2) While sweeping wheel 3 is contacting the blackcolored figure areas (which have electric conductivity) :

a) Switch 22 contacts the lower terminal,

b) Relay 13 works,

c) Switch 21 contacts the lower terminal,

d) Cylinder 10 which memorizes the figure weave acts on solenoid 16 for punching according to the figure weave points.

(3) While sweeping wheel 3 is contacting the greycolored figure areas (which have mild electric conductivity) :

(A) For wefts No. 1, 2, 5 and 6:

a) Switch 22 contacts the lower terminal,

b) Relay 13 stops working (because the electric current is too weak),

c) Switch 21 contacts the upper terminal,

d) Cylinder acts to punch according to the ground weave points.

(B) For wefts No. 3, 4, 7 and 8 :

a) Switch 22 contacts the upper terminal,

b) Electric current is amplified by amplifier 14, and relay 13 works,

c) Switch 21 contacts the lower terminal,

d) Cylinder 10 acts to punch according to the black-colored fisure weave points.

Cylinders 10 and 11 are freely replaceable no matter what kind of ground and figure weaves are.

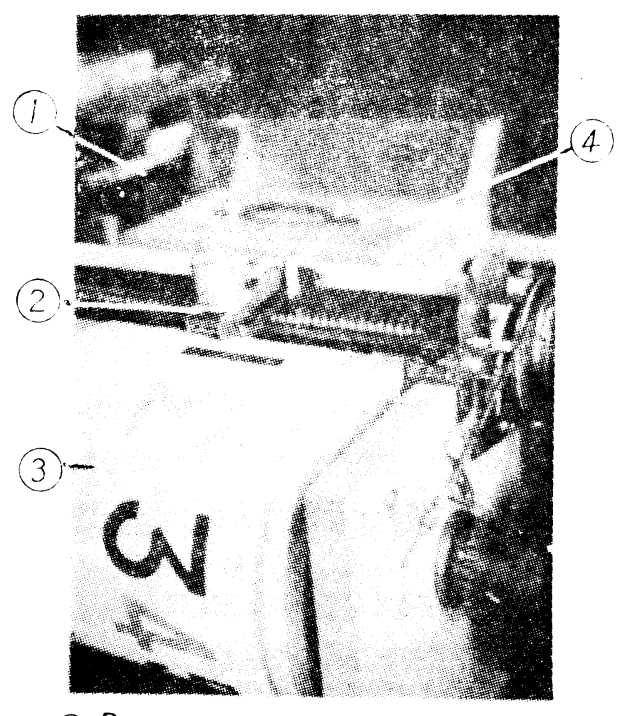

(1) Punching heAD (2) SWEeping WHEEL

(3) FIGURE ON DRUM (4) AMPLIFIER

Fig. 3 Sweeping apparatus

\section{Problem of Border Lines around Design}

The problem of irregularity of punching of the border lines around a design comes from indistinct signals of the sweeping wheel while it is on the border.

The success of our automation effort depends on the degree of the irregularity and on how far it is permissible.

We looked into this question by experimenting with some geometrical patterns, some having circular lines, others oblique lines. We also punched a card with our auto-punching machine and wove a blanket with 
jacquard.

It was difficult to distinguish the irregularity on the woven cloth and it took time to compare the punched holes with the design.

We then hit upon the idea of a punching recorder system.

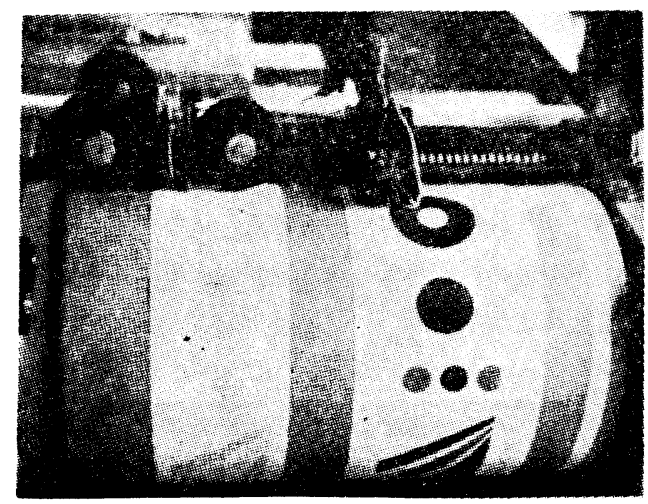

Fig. 4 Figure on drum

Fig. 4 shows a recording device placed on the pattern drum to make recording marks on white paper. This record shows how the figure is punched on the cards.
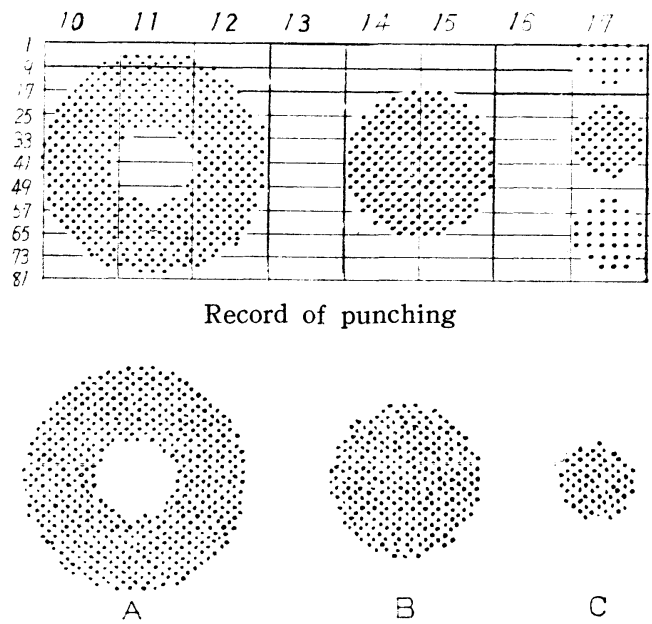

Punching point copy from pattern

Fig. 5 Record of punching

Figs. 5 and 6 compare marks from the recording device with marks made on section papar for the same design for use on the "piano machine."

Fig. 5 shows that no difference is observed between the two methods if figures are large: but that the roundness of the figure is lost if it is a small figure like $\mathrm{C}$, although its outline is not ugly.

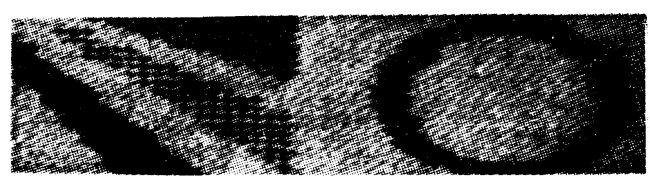

Gray state (off loom)
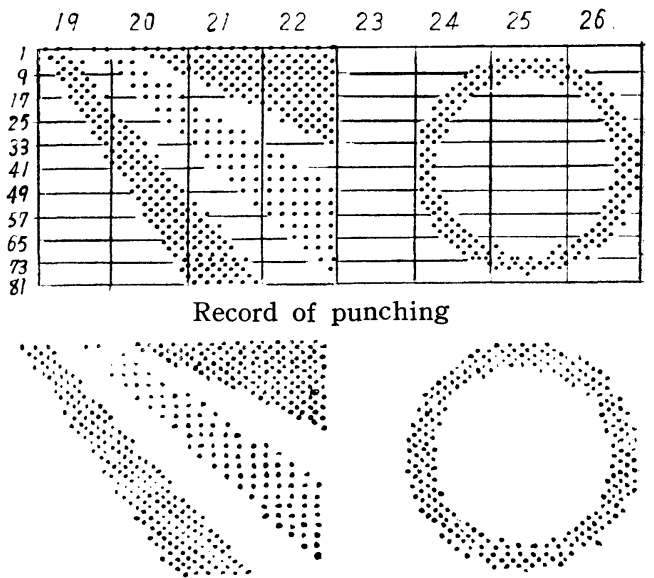

D

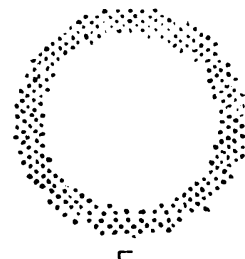

$E$

Punching point from pattern

Fig. 6 Record of punching

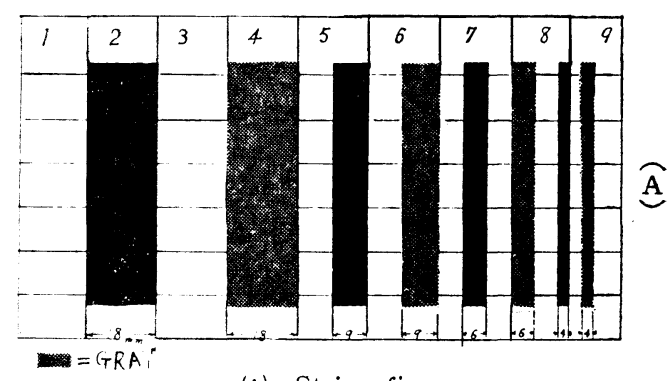

(A) Stripe figure

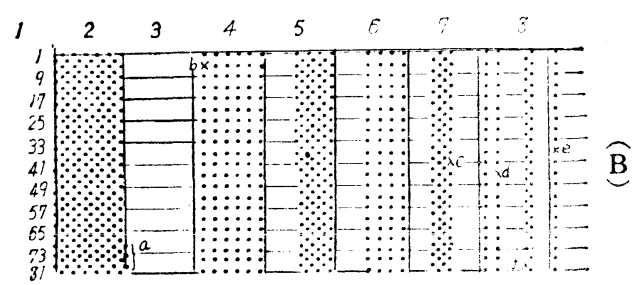

(B) Record of punching

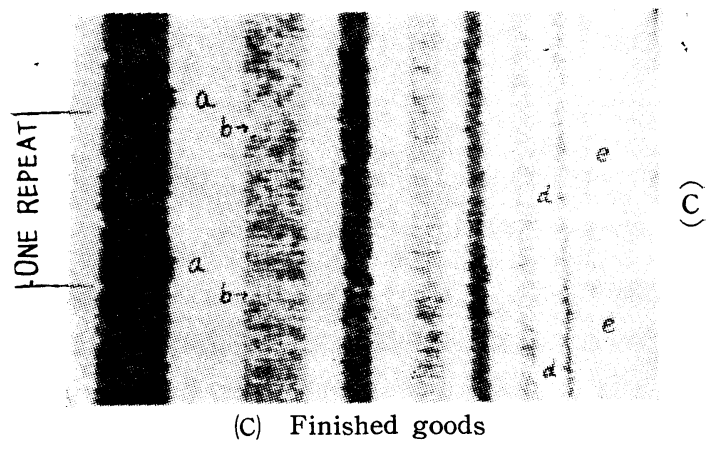

Fig. 7 Trially woven fabric 
In the case of a stripe line in Fig. 7, a portion of its outline is distinctly disturbed. Fig. 7 (A) shows a stripe figure. Fig. 7 (C) shows a test fabric woven with Fig. 7 (B).

Part (a) of Fig. 7 (B) shows extra points perceived. Parts (b), (c), (d), (e) and (f) show points not perceived by the sweeping wheel.

The test fabric shown in Fig. 7 (C) was woven with cards punched by our method and then finished.

It contains deformities, which do not show conspicuously in wide stripes but do show noticeably, in the form of broken stripes, in narrow stripes, such as $\mathrm{d}$ and $\mathrm{e}$.

Incidentally, there is a piece of work which only the automatic sweeping device can do. It is the gradation of patterns (shaded figures). It is a difficult and troublesome task to draw them manually on section paper. With the automatic sweeping device, shaded figures are easily obtainable from a design painted at random, as shown in Fig. 8. A fabric after raising finish is as shown in the picture.

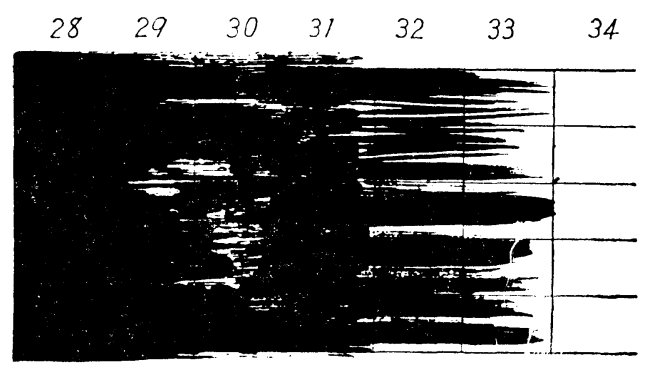

Shaded figure

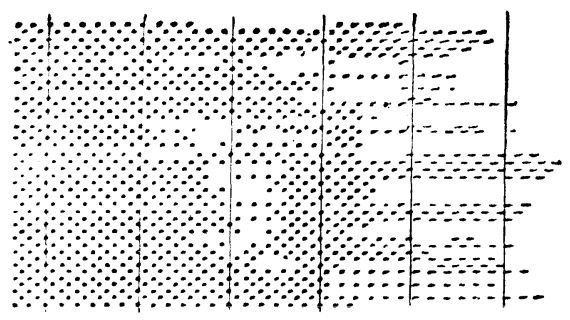

Record of punching

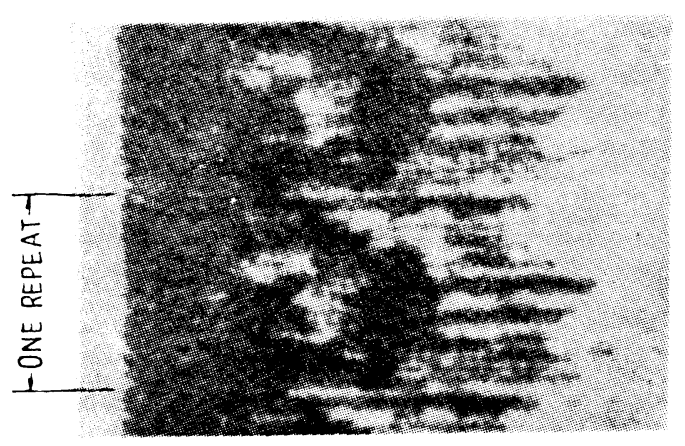

Finished goods

Fig. 8 Trially woven fabric

\section{Conclusions}

Factors contributing to undesirable happenings during automatic card punchng are :

1) Unavoidable irregularity of line which comes from random pick-up.

2) Wrong pick-up of weave points of figure caused by uneven application of electric conductive colours.

3) Wrong pick-up occasionally caused by dust or some foreign substance sticking to paper when the sweeping wheel contacts a design.

4) Occasional failure of the electric drum to be driven synchronously with card-punching.

These factors were revealed by the operation of our model machine. Only factor No. 1 is inherent. The other factors are remediable.

\section{Part 2 Test Weaving of Blanket}

\section{Experiment No. 1}

Part 1 of this article concerned the fidelity with which a design is perceived by sweeping. As the next step, an experiment was made to see whether a service machine could be devised and stably run. The experiment was conducted with the following points in mind : 1) How can border lines be detected, in practice, by the sweeping wheel?

2) Can the difference in electrical conductivity between black and grey colors be detected accurately ?

3) Can the drum be fed synchronously with the punching speed?

4) What remedies are possible for troubles likely to arise from continuous driving of the machine?

A geometrical figure was used in the experiment so that we might distinguish the reasons and the results clearly. The sweeping wheel used was $8 \mathrm{~mm}$. in diameter, $1.2 \mathrm{~mm}$ in width and $85 \mathrm{gr} / \mathrm{cm}^{2}$ in weight (the weight was changed in a later experiment).

\section{Punching Performance}

The punching performance made by our machine is summed up thus :

1) Number of punched cards..........102 sets* $100 \%$

(One set consiste of 2 cards, one for face weave, the other for back weave.)

2) Number of good (correctly punched) cards. .........

37 sets $37 \%$

3) Number of holes made by punching both face and back cards on the border line of figure. .........

129 holes 
4) Number of holes made without punching face or back cards on the border line.................74 holes Combined total of 3) and 4) ….. 203 holes $6.85 \%$

5) Nunber of borders punched, counting from the figure. …....................................2, $960100 \%$

6) Average number of punched holes on the border per set of cards. …............................29 holes

7) Average number of incorrect holes on the border per set of cards. …............................... 2 holes The incorrect holes on the border are about $7 \%$ of the holes on the border. Incorrect holes, except those on the border, are very few; They resulted from imperfect designing or from mis-operation of the machine.

A mis-punched card has to be punched again. For this purpose, the machine must have reproducibility of card punching, especially when used in mills. This reproducibility, illustrated by (3) and (4) in the foregoing tabulation, is $6.85 \%$ inferior.

\section{Experizent No. 2}

Incorrect holes in the frist experiment amounted to $7 \%$. Instances of irregularity of the border line were noticed. The main cause for the incorrect holes was that the drum was often not fed synchronously with the punching speed. In the second experiment, the model machine was equipped with a device to stop the machine in case of non-synchronism of drum-feeding with the punching speed.

\section{Punching Performance}

1) Number of the punched cards ............

(106 sheets) 53 sets.

2) Number of punched holes on the border on both face and back cards ..........................26 pcs.

3) Number of unpunched holes on the border on both face and back cards .............................. pcs.

4) Number of punched holes on the border, counting from the design. …...................... 1, $374100 \%$

5) Average number of punched holes on the border per set of cards …............................ 30.6 pcs.

6) Average number of unpunched holes on the border per set of cards …........................... 0.78 pcs. These results show that the machine turned out to be a major improvement on what it had been in the first experiment. The number of-unpunched holes was now 0.78 per 2 cards. This means that the machine is usable in mills. Fig. 9 shows the test design, a fabric in grey state and finished state.

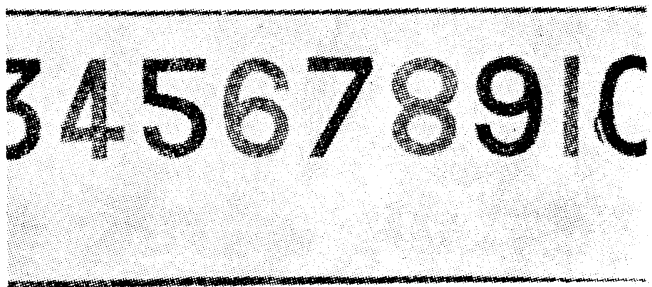

(A) Figure

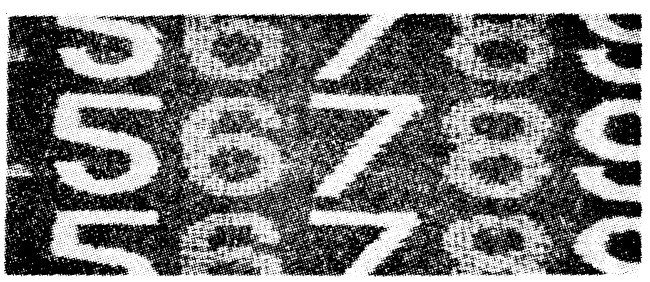

(B) Gray state (off loom)

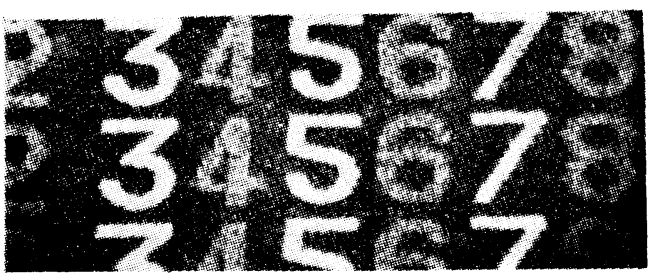

(C) Finished goods

Fig. 9 Trially woven fabric

\section{How to aroid Mis-punching}

A problem common to reversible fabrics is that the same holes are apt to be punched on face and back cards-overlapping of holes-or that holes are not punched on either card on the border line. The correct punching for reversible weave demands that holes on face cards be entirely opposit to those on back cards. Incorrect punching is easily avoidable by using two punching heads and punching both face and back cards at the same time.

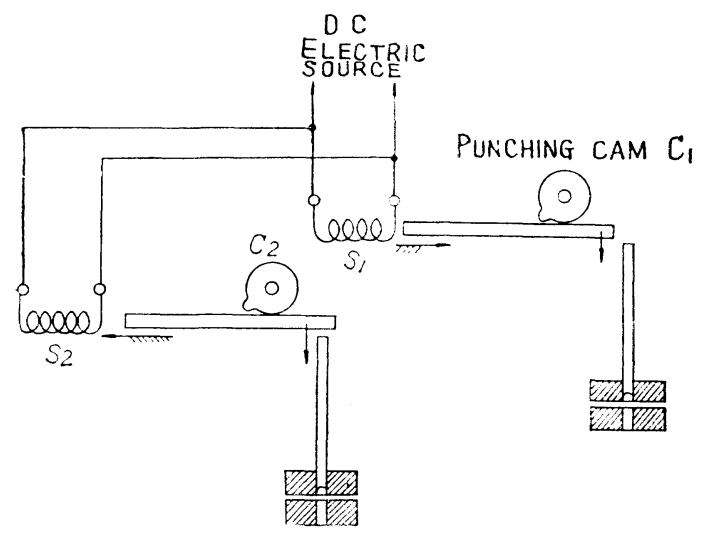

Fig. 10 Double punching head 
Fig. 10 is an example of this method. The example was made with electric solenoids and by suction and repulse actions. Of course, only one solenoid may be used, if its both sides are used.

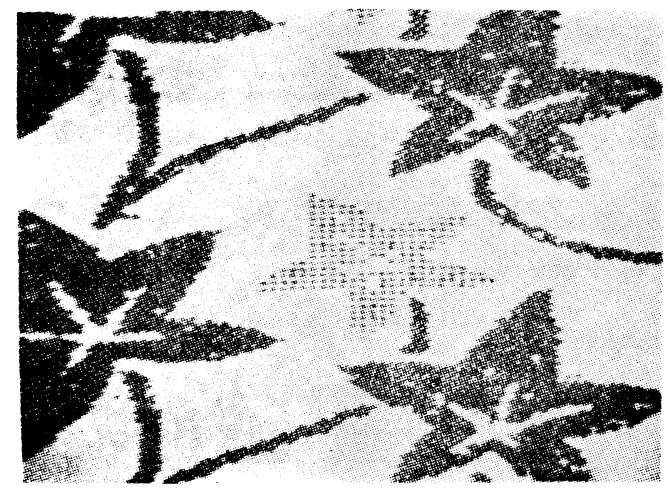

Fig. 11 Ist trially woven fabric mis-punched

Mis-punching is caused also by lack of uniformity in applying electric conductive colors, as shown in Fig. 11, which exhibits spots in the woven figures.

It is extremely difficult to apply electrical conductive colours evenly. It is no less difficult to detect unevenness of color at sight. The unevenness, to be detecled beyond doubt, must be measured through the unevenness of electric resistance. The electric resis. tance values obtained by sweeping the design are given in Table 2.

Let it be noted about the table that the sweeping wheel passed the center of each $1 \mathrm{~cm}^{2}$ section of a design under a pressure of $150 \mathrm{gr} . / \mathrm{cm}^{2}$. The resistance value was measured when the sweeping wheel touched the central point of each section.

The table shows that deviation has large values. A dispersive agent was used to prevent uneven painting, but it was in vain.

Table 2 Resistance Value

\begin{tabular}{l|c|c}
\hline & Black color & Grey color \\
\hline No. of measured places & 60 & 50 \\
\hline Max. resistance & $1.10 \mathrm{~K} \Omega$ & $18 \mathrm{~K} \Omega$ \\
\hline Min. resistance & $0.08 / \prime$ & $5 \quad \prime \prime$ \\
\hline Average resistance & 0.32 & $10 \prime \prime$ \\
\hline Standard deviation & 0.185 & $2.8 \quad \prime$ \\
\hline Coefficient of deviation & $58 \%$ & $28 \%$ \\
\hline
\end{tabular}

\section{Experiment No. 3}

This time we used a photo-electric converter, ins. tead of electric conductive colors. Fig. 12 shows a cross sectional view of the photo electric converter placed in the same position as that of the sweeping wheel. The amplifier and other apparatus used were the same as those previously used.

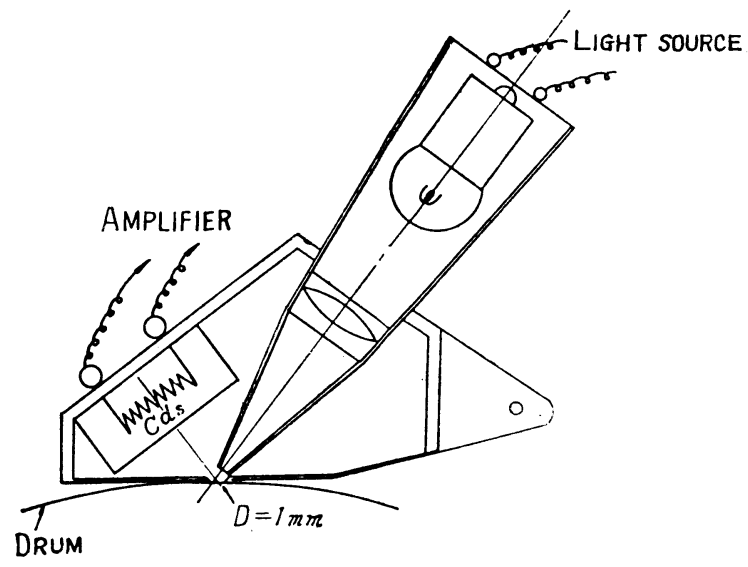

Fig. 12 Photo-electric convertor

In experiments No. 2, black electric conductive color showed the strongest conductivity. With the photo-electric converter used, however, the strongest current was abtained with white. Therefore, cards were punched in an entirely opposite way to the previous experiment. It would have been all right, in this third experiment, to use cards arranged the other way round.
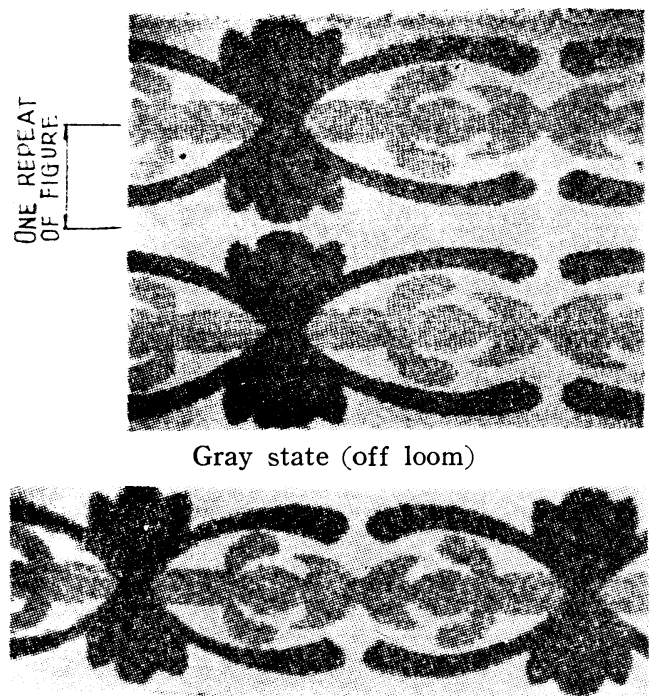

Finished state

Fig. 13 Trially woven fabric

Fig. 13 shows the test fabric woven with cards punched by the photo-electric converter. 


\section{Conclusions}

The technical suggestions obtained from the whole series of experiments are summed up thus :

(1) The intermittent movement of the drum must be accurate. Otherwise the reproducibility of the figure will be poor.

(2) Uniform application of electric conductive colors is vital.

(3) The effective stripe width which the sweeping wheel can detect is a minimum of $3 \mathrm{~mm}$. (equivalent to 2 holes). Lines less than $3 \mathrm{~mm}$. in width had better be avoided when drawing a design.

(4) The rectilinearity in the warp direction is apt to be worse than that made by manual punching. The reason is that the machine punches hole as unevenly as any unevenness in a straight line of a design.

(5) Automatic punching does not make the border line as distinct as manual punching does, but this is harmless to the serviceability of automatic pun- ching.

(6) It is believed that automatic punching of main holes, binding holes, selvage holes, heald holes, etc. is possible.

(7) We used a carbon brush to get the electric pulse of on-off and found that the pulse was disturbed by accumulated carbon dust A noncontact switch is more advisable.

(8) We had no trouble with the amplifier. The relays we used worked accurately but it is better to use relays of a plug-in type.

(9) The automatic card feeder worked accurately, but it is advisable to have a device which stops the machine in case of mis-feeding of cards.

(10) In our experiments, cards were punched in a longitudinal direction. With cards fed in a cross direction on a service machine, the output will be about 300 sheets $/ \mathrm{hr}$.

If a double punching head system is used even in a longitudinal feeding system, the output will be about 60 sheets per hour, which equals the productive capacity of a skilled key puncher. 